\title{
O Efeito de Duas Abordagens de Ensino na Produção Escrita de Alunos de Italiano como Língua Estrangeira
}

The Effect of Two Teaching Approaches on the Italian as a Foreign Language Learners' Written Production

\author{
Paula Garcia de FreItAS (UFPR)
}

Rosely Perez XAVIER (UFSC)

\section{RESUMO}

Este trabalho analisa a produção escrita de dois grupos de estudantes de italiano como lingua estrangeira com o objetivo de relacionar o seu desempenho com a abordagem de ensino recebida. O primeiro grupo recebeu ensino explícito de duas estruturas: presente dell'indicativo e passato prossimo, e o segundo grupo foi submetido ao ensino implícito por meio de atividades comunicativas "encharcadas" com as estruturasalvo, sendo também destacadas no insumo. Unidades didáticas foram elaboradas para atender as abordagens instrucionais. Os dados foram coletados através de pré- e pós-testes e pelas atividades de produção do material elaborado. Os resultados mostraram vantagens diferenciadas para cada grupo.

Palavras-chave: Ensino explícito; Ensino implícito; Produção textual; Italiano como língua estrangeira. 


\section{ABSTRACT}

This paper analyzes the written production of two groups of Italian as a foreign language (ItFL) learners in order to relate their performance to the teaching approach they were exposed to. The first group received explicit instruction on two structures: presente dell'indicativo and passato prossimo, while the second group received implicit instruction with a set of communicative activities containing input flood combined with enhancement of the target structures. Teaching units were designed to meet each approach. The data were collected through pre-and post-tests, and the writing activities from the teaching units. The results showed distinct advantages for each group.

Key-words: Explicit teaching; Implicit teaching; Written production; Italian as a foreign language.

\section{Introdução}

Aparentemente, o ofício de ensinar pode ser considerado uma tarefa simples quando se tem pouca noção sobre a diversidade de sentidos que tal ato pode ter no ambiente educacional. Para alguns, a ideia de ensinar pode estar associada a "professar um saber" (Roldão, 2007:94) ou sistematizar o conhecimento de modo a facilitar a aprendizagem (Housen \& Pierrard, 2005).

Numa perspectiva mais ampla, Ellis (2009) conceitua o ensino de línguas como uma ação sobre a interlíngua do aluno, podendo acontecer de forma direta (pela transmissão do conhecimento) ou indireta (pela construção do conhecimento pelo próprio aluno). Essa visão nos permite considerar abordagens explícitas e implícitas para o ensino da língua estrangeira (LE) / segunda língua (L2) ${ }^{1}$, independentemente do tipo de conhecimento a ser aprendido.

O ensino explícito envolve algum tipo de regra a ser pensada intencionalmente durante o processo de aprendizagem (Dekeyser, 2003). Seu objetivo é promover conhecimento metalinguístico e o domínio consciente das estruturas da LE, podendo ser realizado por meio de

1. Neste trabalho, língua estrangeira (LE) e segunda língua (L2) são tratadas como sinônimas para se referir a uma língua não nativa. 
estratégia dedutiva, em que a regra é apresentada para a sua aplicação, ou por meio de estratégia indutiva, em que os alunos devem descobrir uma regra a partir da análise de dados linguísticos previamente fornecidos. Ambas as estratégias são bastante comuns em livros didáticos de língua italiana como LE (ItLE) utilizados no Brasil. É o caso da Coleção In italiano, ancorada na abordagem estruturalista de ensino (Balthazar, 2009) e da Coleção Espresso (e outras) que privilegiam o procedimento APP: Apresentação de uma estrutura ou função comunicativa, Prática através de exercícios guiados, e Produção por meio de atividades comunicativas que requerem o uso da estrutura/função.

O ensino implícito, por sua vez, busca direcionar a atenção do aprendiz para o significado/ sentido das informações que compreende ou produz e, em decorrência disso, aspectos linguísticos da LE podem ser adquiridos (Focus on meaning - Long \& Robinson, 1998). No ensino implícito, há ainda a possibilidade de induzir a atenção do aprendiz para algum aspecto da LE que se mostra frequente ou saliente no insumo (Focus on form - Long \& Robinson, 1998). Independentemente da abordagem (foco no significado ou foco na forma), o objetivo do ensino implícito é promover aprendizagem da LE sem qualquer tratamento explícito dessa língua (Ellis, 2009).

Norris e Ortega (2000), ao realizarem uma meta-análise de estudos experimentais e quase experimentais sobre a eficácia do ensino explícito e implícito, publicados entre 1980 e 1998, chegaram à conclusão que tipos explícitos de ensino são mais eficazes do que os tipos implícitos. No entanto, é preciso ter cautela ao se chegar a essa conclusão, devido a fatores como: o contexto da pesquisa (laboratório $v s$ sala de aula), a metodologia utilizada (uso de instrumentos que acabam favorecendo a aprendizagem explícita), a duração (estudos de curto prazo vs estudos longitudinais) e o número de participantes envolvidos (poucos vs muitos sujeitos para o poder de generalização dos dados). Além disso, nem todos os aspectos linguísticos, funcionais e pragmáticos de uma LE ou, ainda, os diferentes níveis de complexidade de suas estruturas foram avaliados nesses estudos experimentais e quase experimentais revisados por Norris e Ortega.

O presente trabalho descreve duas abordagens de ensino, uma explícita e outra implícita, ambas conduzidas em contextos educativos 
de adultos aprendendo ItLE, com o objetivo de analisar o efeito de cada uma na produção textual dos alunos contendo estruturas de complexidade distinta: presente dell'indicativo (forma simples) e passato prossimo (forma complexa). É um recorte de uma pesquisa mais ampla (Freitas, 2014) sobre a aprendizagem explícita e implícita dessas estruturas.

Em Italianística ${ }^{2}$, assim como nos estudos com outras LEs, a relação entre estratégias de ensino (explícitas e implícitas) e produção escrita necessita ser aprofundada para que possamos entender como elas influenciam no desenvolvimento da capacidade de os alunos produzirem significados por meio de textos.

$\mathrm{O}$ artigo se divide em quatro seções. A primeira e a segunda discutem, respectivamente, o ensino explícito e implícito e as teorias de aprendizagem associadas a essas práticas. A terceira seção apresenta a metodologia do estudo: os participantes da pesquisa, as unidades didáticas produzidas, os instrumentos de coleta e a forma de análise dos dados. Na quarta e última seção, os dados são apresentados e discutidos. $\mathrm{O}$ artigo finaliza com as conclusões e limitações do estudo.

\section{Abordagens de ensino explícito}

O ensino explícito busca evidenciar um aspecto da língua com o objetivo de o aluno aprendê-lo conscientemente. É geralmente caracterizado como uma intervenção do professor que apresenta as formas linguísticas, propõe a sua prática, usa a terminologia metalinguística e requer a atenção direta dos alunos sobre elas (Housen \& Pierrard, 2005). É o que Long e Robinson (1998) denominam de abordagem com foco naS formaS.

Teoricamente, o ensino explícito gera conhecimento explícito. Esse conhecimento é caracterizado por Hulstijn (2005) como sendo simbólico, formado por conceitos e categorias. Para Ellis (2004), o conhecimento explícito caracteriza-se por ser declarativo e factual, e fica armazenado de maneira consciente, sendo acessado através do processamento controlado ou automatizado em decorrência da prática. 
O ensino explícito tem suas raízes em diversas teorias de aprendizagem, como o behaviorismo (Skinner, 1945), a Teoria Cognitiva (McLaughlin, 1987) e a Teoria de Aquisição de Habilidades (Anderson, 1982, 1993; Dekeyser, 1998). O behaviorismo caracteriza-se pela criação e pelo fortalecimento de hábitos positivos por meio de respostas imediatas a estímulos linguísticos externos, acompanhado de feeback positivo. Nessa perspectiva, aprender LE significa fomentar a prática mecânica, a imitação, o condicionamento, o reforço, a padronização, a modelagem, a repetição e a memorização.

Em oposição ao behaviorismo, que atribui ao meio ambiente papel determinante para a aprendizagem da LE por práticas de estímulo-resposta-reforço, a Teoria Cognitiva, defendida por McLaughlin (1987:133), parte do princípio de que a aprendizagem de LE é um "processo cognitivo", uma vez que envolve "representações internas que regulam e orientam o desempenho na língua". Essas representações se formam a partir do processamento controlado e automático da informação, além de outros processos envolvidos, como o refinamento (tuning) e a restruturação (restructuring). A aprendizagem de LE é, portanto, regulada pelo processamento controlado, o qual exige a atenção focada do aprendiz sobre a informação a ser aprendida. Essa informação só será transferida para a memória de longo prazo através do processamento automatizado. Essa visão de aprendizagem se assemelha à Teoria de Aquisição de Habilidades ${ }^{3}$.

Anderson $(1982,1993)$ defendeu um modelo de aquisição de habilidades, denominado ACT (Adaptative Control Theory - Teoria do Controle Adaptativo), que consiste em dois estágios: o estágio declarativo (declarative stage) e o procedimental (procedural stage). No primeiro, "o aluno recebe instruções e informações sobre a habilidade. A instrução é codificada em um conjunto de fatos sobre a habilidade, e esses fatos podem ser colocados em uso a partir de procedimentos interpretativos gerais para gerar comportamento" (Anderson, 1982:379). É no segundo estágio que o conhecimento declarativo é convertido em uso. O estágio procedimental fortalece as produções interpretativas do conhecimento declarativo e as torna de fácil acesso (automatizadas), alojando-as na

3. O termo habilidade refere-se a "domínios que variam desde a aprendizagem de sala de aula (leitura, aprendizagem de línguas) até a aplicação de habilidades no campo dos esportes e da indústria" (Dekeyser, 2007:97). 
memória de longo prazo. A automatização do conhecimento ocorre por meio da prática, entendida como "o engajamento em uma atividade com o objetivo de se tornar melhor nela" (Dekeyser, 1998:50).

Para o ensino da gramática, por exemplo, a procedimentalização e a automatização do comportamento está na aplicação da regra por meio de exercícios (des)contextualizados (prática estrutural) e/ou de atividades que requerem o seu uso em situações de comunicação (prática comunicativa). O objetivo da prática é fortalecer, aperfeiçoar e automatizar o conhecimento procedimentalizado recém-adquirido, aumentando a velocidade, diminuindo a taxa de erros e a demanda sobre os recursos cognitivos (Dekeyser, 1998). Dessa forma, o conhecimento deixa de ser explícito e controlado para se tornar automático.

No presente estudo, o ensino explícito seguiu a Teoria de Aquisição de Habilidades de Anderson, e consistiu no ensino dedutivo de duas estruturas linguísticas do ItLE de complexidades diferentes (presente dell'indicativo e passato prossimo), seguido de sua prática por meio de exercícios des- e contextualizados, e a sua produção em contexto de uso comunicativo, adotando assim a sequência metodológica APP - Apresentação, Prática e Produção. O momento da produção consistiu em tarefas escritas, como relatos, opiniões, listagens e a elaboração de uma notícia.

\section{Abordagens de ensino implícito}

O ensino implícito é definido como uma ação pedagógica que privilegia experiências com o uso da LE para a compreensão e produção de significados. Esse tipo de ensino se apoia na Hipótese da Percepção Consciente (Noticing Hypothesis - Schmidt, 1990, 1995, 2001, 2010) ou inconsciente do aprendiz (Detection - Tomlin \& Villa, 1994). Independentemente da disputa teórica sobre a presença ou ausência de consciência (awareness) ${ }^{4}$ na aprendizagem implícita, o que importa

4. Para Schmidt (1995), a atenção focal e a consciência (awareness) estão inter-relacionadas, diferente do que Tomlin e Villa (1994) defendem. Para eles, ambas estão dissociadas. 
para esses e outros autores é que aprender uma LE requer a atenção do aprendiz e, portanto, compreende processos cognitivos.

Se considerarmos a atenção como fator essencial para a assimilação de formas presentes no insumo, e um precursor necessário para a formação e verificação de hipóteses, cabe ao ensino implícito direcionar ou atrair a atenção dos alunos para formas linguísticas em uso comunicativo.

A atenção pode ser gerada por uma demanda do próprio aprendiz ou do professor. No primeiro caso, ela envolve percepção autogerada (aprendizagem acidental). Fatores como necessidade comunicativa, conhecimento prévio da LE e as diferenças que o aprendiz percebe entre sua língua materna e a LE podem afetar sua percepção sobre o que aprender (Park, 2011). No segundo caso, o professor promove saliência no insumo para gerar atenção focada do aprendiz. Diferentes estratégias podem ser utilizadas, como a presença frequente de amostras ou exemplares de uma determinada forma linguística no insumo (input flooding - insumo encharcado) ou, então, o destaque em uma ou mais formas linguísticas (input enhancement - insumo destacado) por meio de recursos tipográficos para criar impacto visual (Sharwood Smith, 1993). Tais estratégias, utilizadas no ensino implícito, visam a capturar a atenção do aprendiz para determinados aspectos da LE e, dessa forma, promover percepção consciente (noticing), primeiro passo para a construção da língua, segundo Schmidt (2001).

Para Schmidt (1995:29), noticing é o "registro consciente da ocorrência de algum evento". Refere-se a fenômenos percebidos conscientemente no nível superficial, e é condição necessária e suficiente para converter o insumo disponível em insumo assimilado (intake).

No presente estudo, o ensino implícito baseou-se na Hipótese da Percepção Consciente - Noticing (Schmidt, 1990, 1995, 2001, 2010). Para isso, os alunos foram expostos a um conjunto de atividades comunicativas contendo insumo duplamente encharcado e destacado das seguintes estruturas: presente dell'indicativo e passato prossimo, sem qualquer instrução prévia (ensino explícito). O alto índice de ocorrência dessas estruturas no insumo e o seu destaque poderiam promover a sua aprendizagem (Han et al., 2008), em virtude da condição que se cria para uma percepção induzida dessas estruturas. 
No ensino implícito proposto para esta pesquisa, o uso das estruturas-alvo aconteceu por meio de atividades de compreensão e produção escrita e oral, todas de natureza comunicativa.

\section{Metodologia do estudo}

Dois grupos de estudantes de ItLE (G1 e G2) participaram do presente estudo. Para a formação desses grupos, dois cursos paralelos de extensão para iniciantes dessa língua foram ofertados junto ao Departamento de Línguas Estrangeiras Modernas da UFPR e intitulados "Italiano para o dia-a-dia". Cada curso teve carga horária total de 22 horas em 11 encontros de 2 horas, sendo um encontro por semana.

O G1 foi composto por 2 homens e 4 mulheres entre 18 e 56 anos, sendo eles expostos ao ensino explícito das duas estruturas-alvo da pesquisa (presente dell'indicativo e passato prossimo). O G2 compreendeu 2 homens e 6 mulheres entre 19 e 60 anos de idade, que foram submetidos ao ensino implícito dessas mesmas estruturas.

No G1, a maioria dos alunos (4) afirmou que estava tendo o seu primeiro contato com a língua italiana no curso oferecido, com exceção de dois alunos. Um deles (AE1) $)^{5}$ disse ter vivenciado um contexto de imersão quando trabalhava em um navio e o seu colega de quarto era italiano. O outro (AE5) havia estudado formalmente a língua italiana por dois anos, mas pediu para frequentar o curso por achar que sua experiência "não tinha sido produtiva". No G2, nenhum dos participantes havia estudado italiano formalmente, mas a maioria (5) afirmou ter contato com essa língua por meio de músicas, filmes e internet. Um deles (AI8) havia morado na Itália por 2 meses, aprendendo o idioma por imersão.

5. Nesta pesquisa, AE corresponde aos alunos que frequentaram o curso explícito e AI os alunos que participaram do curso implícito. Os números que seguem a abreviatura listam os participantes do grupo. 


\subsection{As unidades de ensino}

Para analisar o efeito de cada abordagem de ensino na produção textual do G1 e G2, quatro unidades didáticas foram desenvolvidas: duas unidades para o G1 (presente e passato prossimo) e duas para o G2 (presente e passato prossimo).

Essas estruturas (presente e passado) foram escolhidas pelas seguintes razões: primeiro, porque o conhecimento desses tempos verbais é considerado essencial para que o usuário dito "elementar" no QECR ${ }^{6}$ se comunique. Nesse nível de aprendizagem o usuário deve ser capaz de falar de assuntos familiares e descrever a própria experiência de maneira simples (Conselho da Europa, 2001:49). Consideramos que, para falar da própria experiência, é necessário saber usar os verbos no presente e passato prossimo.

Outra razão está no valor implicacional de ambos os tempos verbais, isto é, o conhecimento do passato prossimo implica o conhecimento do presente dell'indicativo e, por essa razão, são os primeiros a serem adquiridos considerando os estágios aquisicionais do sistema verbal (Banfi \& Bernini, 2003).

A complexidade linguística também foi fator decisivo para a escolha dessas estruturas, pois a formação do presente dell'indicativo é menos complexa do que a formação do passato prossimo. Para se ter uma ideia, o presente dell 'indicativo apresenta semelhanças com o seu correspondente no português. Assim como nessa língua, no italiano as terminações do infinitivo -are, -ere e -ire são removidas do radical, ao qual são acrescentadas as desinências verbais do presente (Dardano \& Trifone, 2002). Portanto, para a sua conjugação, estão envolvidos somente alguns componentes morfológicos (desinência verbal de número e pessoa do presente do indicativo), como na língua materna dos participantes desta pesquisa.

O passato prossimo, por outro lado, é um tempo verbal composto ( ho fatto) e pode ser considerado uma estrutura complexa para falantes do português por não seguir a morfologia do pretérito perfeito dessa língua ( $f i z$ ). Para a formação do passato prossimo, é necessário o uso de

6. Quadro Europeu Comum de Referência para as Línguas. 
um verbo auxiliar (essere ou avere) que, além de ter uso e significado próprios (essere = 'ser' e 'estar' / avere = 'ter'), "permite a formação dos tempos compostos com valor de passado" (Serianni, 1989:391). Esses verbos auxiliares, conjugados no presente e seguidos de particípio passado do verbo principal, formam o passato prossimo desse verbo. Assim, as construções "è partita" e "ho visto" correspondem a "partiu" e "vi" na língua portuguesa.

A complexidade desse tempo verbal se acentua quando o aluno tem que definir o auxiliar a ser usado junto ao particípio passado do verbo principal. De acordo com Sabatini (1984), verbos transitivos diretos e alguns indiretos pedem o auxiliar avere, enquanto verbos impessoais na voz passiva e intransitivos requerem o auxilar essere. Mesmo com essa classificação, "não é possível dar uma regra que permita estabelecer qual auxiliar deva ser usado com cada verbo intransitivo" (Serianni, 1989:392). Soma-se a esse fato o particípio passado do verbo principal ter que concordar com o sujeito em gênero e número quando o auxiliar for essere. Em exemplos como Paolo è partito, Maria è partita, Paolo e Leonardo sono partiti e Anna e Maria sono partite, a desinência final do particípio passado muda: $-o$ e $-a$ indicam, respectivamente, a forma singular do gênero masculino e feminino, enquanto que as desinências $-i \mathrm{e}-e$ indicam o masculino e o feminino plural. Por outro lado, se o auxiliar for avere, o particípio passado não sofre alteração ${ }^{7}$, conforme Sabatini (1984).

As unidades produzidas para o G1 privilegiaram o ensino dedutivo das estruturas-alvo, acompanhado de exercícios descontextualizados e contextualizados, finalizando com a prática comunicativa. Em cada unidade (uma para o presente e a outra para o passado), um quadro explicativo da estrutura-alvo foi fornecido e, juntamente com a explicação da professora ${ }^{8}$, configurava a fase de apresentação da estrutura.

Na sequência, duas atividades foram propostas na forma de exercícios: uma com sentenças para serem completadas com a forma correta dos verbos fornecidos, e a outra com mini textos para serem completados com o verbo definido pelo aprendiz de acordo com o sentido do 
texto, ambas configurando a fase da prática estrutural. Esses exercícios privilegiaram a conjugação de verbos na $1^{\mathrm{a}}$ pessoa do singular $(i o), 3^{\mathrm{a}}$ pessoa do singular (lei, lui) e $3^{\mathrm{a}}$ pessoa do plural (loro).

A última seção das unidades de ensino do G1 consistiu em três atividades comunicativas, cada qual destinada a suscitar a produção escrita-oral de verbos na $1^{\text {a }}$ pessoa do singular, $3^{\mathrm{a}}$ pessoa do singular e $3^{\mathrm{a}}$ pessoa do plural, respectivamente. Essas atividades também estiveram presentes nas unidades de ensino do G2 para fins de comparação.

As unidades elaboradas para o G2, por sua vez, contemplaram atividades comunicativas. Elas envolveram as estruturas-alvo destacadas (em negrito, sublinhadas e em fonte 14) e encharcadas em textos didatizados ${ }^{9}$.

Um total de 18 atividades comunicativas foi elaborado, 9 para a unidade do presente dell'indicativo e 9 para a unidade do passato prossimo. Em cada unidade de ensino, as três primeiras atividades (Seção 1) visaram a atrair a atenção dos alunos para as formas verbais de $1^{a}$ pessoa do singular. As três atividades seguintes (Seção 2) lidaram com verbos na $3^{\text {a }}$ pessoa do singular, e as três últimas atividades (Seção 3) direcionaram a atenção dos alunos para verbos na $3^{\mathrm{a}}$ pessoa do plural.

A primeira atividade de cada seção iniciava com a leitura de um texto contendo os verbos conjugados na pessoa-alvo em destaque, com o objetivo de induzir a atenção dos alunos sobre as conjugações, para então fomentar a produção escrita e oral. Seguem dois enunciados de atividades comunicativas utilizadas no material:

Attività 1 - Leggi i post con le descrizioni delle giornate di due persone. In base alle descrizioni, completa il quadro, in portoghese, con le cose che fanno. Alla fine, racconta a tutto il gruppo quali sono le azioni comuni tra $i$ due personaggi. Racconta in italiano.

[Atividade 1 - Leia os posts com as descrições do dia-a-dia de duas pessoas. Com base nas descrições, complete o quadro, em português, com as coisas que elas fazem. Ao final, relate para toda a classe as ações em comum entre os dois personagens. Faça o seu relato em italiano.]

9. Segundo Cepollaro (2003), o texto didatizado nasce do material autêntico sobre o qual são feitas algumas adaptações para fins de compreensão e percepção consciente (noticing). 


\begin{abstract}
Attività 2 - Guarda il video di una donna che fa turismo a Venezia. Fa' attenzione alle azioni che la turista realizza e identifica quale dei due diari di viaggio riproduce la sua giornata nella città. Alla fine, di' quali informazioni non vanno d'accordo con il video.

[Atividade 2 - Assista ao vídeo de uma turista que passeia por Veneza. Preste atenção às ações que ela realiza e identifique qual dos dois diários de viagem reproduz o seu dia na cidade. Ao final, relate as informações que não correspondem ao que é apresentado no vídeo.]
\end{abstract}

Para comparar o desempenho dos grupos, as unidades didáticas centraram em verbos regulares em -are, -ere e -ire, flexionados na $1^{\mathrm{a}}$ e $3^{\text {a }}$ pessoas do singular e na $3^{\text {a }}$ pessoa do plural, com especial atenção ao verbo pulire nessas três pessoas, que é flexionado com -ISC, e os irregulares fare (fazer) e andare (ir). Essa delimitação foi necessária para evitar excesso de saliência no insumo.

Vale ressaltar que os enunciados de todas as atividades do material foram redigidos em italiano, assim como as aulas foram conduzidas nessa língua em ambos os grupos.

\title{
3.2. Coleta e análise de dados
}

Para este artigo, os dados consistiram nos textos escritos que os alunos redigiram em dois testes aplicados em três momentos distintos. O primeiro teste envolveu o uso do presente dell 'indicativo e o segundo teste, o passato prossimo. Cada teste compreendeu três atividades de produção escrito-oral, cujos enunciados foram redigidos em português para melhor compreensão dos alunos, conforme mostra o Quadro 1. 
Quadro 1 - Enunciados das atividades dos testes 1 e 2.

\begin{tabular}{|c|c|c|}
\hline & $\begin{array}{c}\text { Teste } 1 \\
\text { Presente dell'indicativo }\end{array}$ & $\begin{array}{c}\text { Teste } 2 \\
\text { Passato prossimo }\end{array}$ \\
\hline Attività 1 & $\begin{array}{l}\text { O que você faz durante o dia? } \\
\text { Você tem cinco minutos para } \\
\text { planejar sua resposta em italiano, } \\
\text { no quadro abaixo. Ao término dos } \\
5 \text { minutos, você vai gravar sua } \\
\text { resposta em áudio. }\end{array}$ & $\begin{array}{l}\text { Suponha que você tenha visitado } \\
\text { a cidade de Roma no ano passado. } \\
\text { O diário abaixo registra, de forma } \\
\text { sintética, as coisas interessantes que } \\
\text { você fez. Com base nele, conte aos } \\
\text { seus amigos italianos o que você fez. } \\
\text { Você tem } 10 \text { minutos para planejar } \\
\text { sua resposta em italiano e gravar a } \\
\text { sua fala em áudio, como se estivesse } \\
\text { contando a sua viagem para os seus } \\
\text { amigos. }\end{array}$ \\
\hline Attività 2 & $\begin{array}{l}\text { Observe as imagens e relate, em } \\
\text { italiano, o que Maria faz durante } \\
\text { o dia. Você tem cinco minutos para } \\
\text { planejar sua resposta no quadro } \\
\text { abaixo. Ao término dos } 5 \text { minutos, } \\
\text { você vai gravá-la em áudio. }\end{array}$ & $\begin{array}{l}\text { "PARAAS MENINAS - Suponha que } \\
\text { você achou a agenda de um rapaz que } \\
\text { a sua amiga italiana está paquerando. } \\
\text { Antes de devolver, você avisa a sua } \\
\text { amiga, que fica curiosa para saber o } \\
\text { que o rapaz fez no sábado passado. A } \\
\text { agenda abaixo registra todas as ações } \\
\text { do rapaz. Com base nela, conte tudo o } \\
\text { que ele fez nesse dia para a sua amiga. } \\
\text { Você tem } 10 \text { minutos para planejar } \\
\text { sua resposta em italiano e gravar a } \\
\text { sua fala em áudio. }\end{array}$ \\
\hline Attività 3 & $\begin{array}{l}\text { Carlo e Anna são casados e fazem } \\
\text { juntos diversas atividades. Abaixo } \\
\text { estão listadas as ações que o } \\
\text { casal realiza ao longo da semana. } \\
\text { Relate-as oralmente em italiano, } \\
\text { mas, primeiro, você tem cinco } \\
\text { minutos para planejar sua resposta } \\
\text { no quadro abaixo. Ao término dos } \\
5 \text { minutos, você vai gravar sua } \\
\text { resposta em áudio. }\end{array}$ & $\begin{array}{l}\text { Suponha que, em sua viagem à Itália, } \\
\text { você tenha presenciado um assalto a } \\
\text { um supermercado. As imagens abaixo } \\
\text { retratam o que você viu. Com base } \\
\text { nessas imagens, conte ao policial } \\
\text { italiano tudo o que aconteceu. Você } \\
\text { tem } 10 \text { minutos para planejar sua } \\
\text { resposta em italiano, no quadro } \\
\text { abaixo. Ao término desse tempo, } \\
\text { grave a sua fala em áudio. }\end{array}$ \\
\hline
\end{tabular}

*. Uma versão correspondente aos meninos também foi fornecida neste teste para que o contexto pudesse ser diferenciado para os alunos do sexo feminino e masculino. 
Cada teste foi aplicado em três momentos distintos: (1) antes da implementação da unidade de ensino correspondente à estrutura-alvo (pré-teste), (2) depois de a unidade ser concluída (teste imediato) e (3) duas semanas após a implementação da unidade (teste postergado). $\mathrm{O}$ objetivo foi avaliar as produções textuais dos alunos antes e após a abordagem de ensino recebida (pré-teste $\rightarrow$ teste imediato) e entre o término da instrução e após um tempo prolongado de assimilação da estrutura (teste imediato $\rightarrow$ teste postergado).

As atividades comunicativas do material instrucional do G1, também presentes no material do G2 para fins de comparação, geraram dados que também foram considerados na análise. A produção escrita dos alunos nessas atividades, no pré-teste e nos pós-testes (imediato e postergado) foi analisada em termos de precisão gramatical no uso das estruturas-alvo, natureza dos erros, complexidade sintática e discurso produzido.

É importante salientar que o emprego correto de uma estrutura linguística não implica necessariamente a sua adequação no contexto de uso, como já afirmava Widdowson (1978). Por essa razão, para este estudo, a precisão gramatical foi analisada a partir da incidência total de erros no texto do aluno pelo número de $T$-units ${ }^{10}$ (erros/ $T$-unit). Quanto mais próximo de zero for o número de erros, melhor o desempenho do aluno em sua produção escrita.

A conversão dos textos em T-units permitiu ainda avaliar a complexidade sintática. De acordo com Ellis e Barkhuizen (2005), produções formadas majoritariamente por orações independentes sugerem um nível de complexidade menor do que produções contendo orações coordenadas e subordinadas. Procurou-se verificar o incremento no número de orações subordinadas nas produções dos alunos do préteste para os pós-testes. Na próxima seção, analisamos as produções escritas dos alunos.

10. T-unit é a "menor unidade na qual um trecho do discurso pode ser cortado sem deixar fragmentos de frases como resíduos" (Hunt, 1970:189), o que permite "quantificar o discurso" (Polio, 1997:120). Ela é formada por uma oração independente e por todas as 


\section{Análise e discussão dos dados}

Os dados permitiram afirmar que as abordagens de ensino, tanto explícita como implícita, tiveram efeitos positivos nas produções textuais dos alunos, demonstrando diminuição de erros em construções verbais de $1^{\mathrm{a}}$ e $3^{\mathrm{a}}$ pessoas do singular e de $3^{\mathrm{a}}$ pessoa do plural do presente dell indicativo e do passato prossimo, observada nos pós-testes.

Os gráficos 1 e 2, a seguir, sintetizam os resultados ${ }^{11}$ de ambos os grupos no uso das duas estruturas, sinalizando uma queda considerável no número de erros por T-unit do pré-teste para o teste imediato.

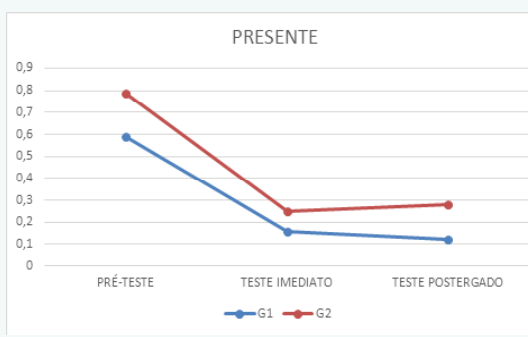

Gráfico 1. Desempenho do G1 e G2 quanto ao uso do presente dell'indicativo.

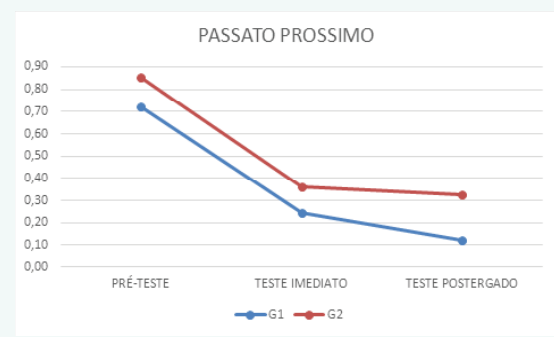

Gráfico 2. Desempenho do G1 e G2 quanto ao uso do passato prossimo.

Os gráficos acima mostram que o ensino explícito foi mais eficaz do que o ensino implícito para o uso da estrutura simples (presente dell'indicativo) e complexa (passato prossimo) nas produções textuais postergadas. Este dado corrobora autores que sugerem haver relação entre o tipo de ensino e a aprendizagem de determinadas formas linguísticas (Schmidt, 1995; Williams \& Evans, 1998). Williams e Evans (1998) e Andrews (2007), por exemplo, concluíram que o uso da estratégia explícita foi mais influente na aprendizagem de estruturas complexas (voz passiva e orações relativas) em relação à estratégia implícita utilizada, o que também parece ser o caso desta pesquisa com a estrutura do passato prossimo. Igualmente, Williams e Evans (1998, cf. 232-233) afirmaram que estratégias explícitas apresentam melhores resultados para o aprendizado de estruturas simples (facil- 
mente verbalizadas), o que também corrobora os resultados obtidos neste estudo, no teste postergado.

Segundo Han et al. (2008:612), "o ensino explícito é conhecido por ser rápido em provocar mudanças superficiais instantâneas no comportamento do aprendiz em comparação ao ensino implícito, cujo impacto na aprendizagem - especialmente no domínio da morfossintaxe - pode levar tempo para ser construído e sentido". Pelo fato de o G2 ter vivenciado um ensino que dividia sua atenção entre o significado pragmático e a forma linguística (Foco na Forma - Long \& Robinson, 1998), mais tempo seria necessário para a apropriação de ambas as estruturas.

Isso não significa dizer que o G2 não fora capaz de utilizar as estruturas-alvo corretamente em suas produções textuais. No teste postergado, cinco alunos do G2 foram capazes de acertar 100\% das conjugações utilizadas em suas produções, como a forma verbal de $1^{\text {a }}$ pessoa do singular da estrutura simples (AI3 e AI6) e complexa (AI8), $3^{\text {a }}$ pessoa do plural da estrutura simples (AI8) e $3^{\text {a }}$ pessoa do singular da estrutura complexa (AI5, AI7). O mesmo aconteceu com quatro alunos do G1 nas seguintes pessoas do discurso: $3^{\mathrm{a}}$ pessoa do singular da estrutura complexa (AE1, AE3, AE6) e a $3^{\text {a }}$ pessoa do plural da estrutura simples (AE4, AE6) e complexa (AE3, AE4).

Se, por um lado, alguns alunos do G1 e G2 evidenciaram o domínio pleno das estruturas-alvo no teste postergado (em determinadas pessoas do discurso e no tempo presente / passado), por outro, houve alunos (do G2, principalmente) que apresentaram oscilações entre o uso correto e incorreto das estruturas-alvo.

A coexistência do uso correto e incorreto de uma determinada forma verbal do presente ou passado foi observada em um mesmo texto e, também, em momentos diferentes da produção textual dos alunos. No exemplo a seguir, AI1 utiliza formas corretas e incorretas para os verbos fare (faccio, facchio*) e mangiare (mangio, manjo*), sugerindo que as estruturas estavam ainda em processo de apropriação.

AI1: Io me alzo alla nove e faccio la colazione. Io no mangio molto la mattina. Dopo, io accendo el PC e lavoro alla mezzogiorno. Io preparo il pranzo e manjo* avante la TV. Alle tredici io pulisco la casa, dopo io lavoro el PC. Alla diciasete io faccio la duccia e alle diciotto io preparo la cena. Io ceno 
con mio marito, leggio* e studio, guardamos la tv e alle omdici, io voi* a dormire. Quase tutti giorni della settimana, io facchio questo.

Do teste imediato para o teste postergado, o percentual de acertos das estruturas-alvo diminuiu, principalmente para os alunos do G2, que utilizaram construções verbais corretas no teste imediato, mas que, no teste postergado, essas construções foram formuladas incorretamente. A tabela abaixo ilustra alguns exemplos de altas porcentagens de acertos das estruturas-alvo no teste imediato, mas que não se mantiveram no teste postergado, gerando assim instabilidade no seu uso.

Tabela 1 - Percentual de acertos no teste imediato e postergado para alguns alunos do G1 e G2.

\begin{tabular}{c|l|c|c}
\hline G1/G2 & \multicolumn{1}{|c|}{ Forma verbal / estrutura-alvo } & Teste imediato & Teste postergado \\
\hline AE4 & $\begin{array}{l}1^{\text {a }} \text { pessoa do singular do presente do } \\
\text { indicativo }\end{array}$ & $62 \%$ & $47 \%$ \\
\hline AE2 & $\begin{array}{l}1^{\text {a }} \text { pessoa do singular do passato } \\
\text { prossimo }\end{array}$ & $92 \%$ & $85 \%$ \\
\hline AI4 & $\begin{array}{l}3^{\text {a }} \text { pessoa do singular do presente do } \\
\text { indicativo }\end{array}$ & $83 \%$ & $30 \%$ \\
\hline AI5 & $\begin{array}{l}1^{\text {a }} \text { pessoa do singular do passato } \\
\text { prossimo }\end{array}$ & $75 \%$ & $58 \%$ \\
\hline
\end{tabular}

Essa diminuição no percentual de acertos sugere que esses alunos estavam em processo de restruturação ${ }^{12} \mathrm{ou}$, possivelmente, em curvas de aprendizagem em forma de U (U-shaped learning curve $)^{13}$, indicando que estavam em processo de transição entre padrões baseados em regras e padrões associativos com outras estruturas. Esses e outros dados sugerem que a aprendizagem não é um processo monolítico, linear e acumulativo de melhorias (Carlucci \& Case, 2013).

12. Restruturação são "mudanças qualitativas que acontecem quando a informação é reorganizada em novas categorias." (cf. RESTRUCTURING. In An A-Z of ELT [online]. Disponível em: $<$ https://scottthornbury.wordpress.com/tag/restructuring/>. Acesso em: 19 jan. 2017.

13. "[...] a aprendizagem em forma de $\mathrm{U}$ é um comportamento em que o aluno inicialmente aprende o correto e, então, abandona esse comportamento e, finalmente, retorna a ele" (Carlucci \& Case, 2013:57), gerando uma curva em U. 
Outro aspecto interessante observado nos textos dos alunos foi a natureza dos erros. No G1, as produções pareceram ter recebido maior influência da língua materna e de outras línguas (erros interlinguais), enquanto que as produções do G2 apresentaram maior influência da língua-alvo (erros intralinguais). Essas influências podem estar associadas ao tipo de ensino recebido. No ensino explícito, marcado por exercícios descontextualizados e distantes da linguagem como prática social, maior incidência de transferência da L1 poderia acontecer, pois os alunos contam com, basicamente, processamentos ascendentes (bottom-up processing) para a sua aprendizagem.

No ensino implícito, por outro lado, processamentos ascendentes e descendentes (top-down processing) contribuem para a compreensão e a aprendizagem da LE. Cabe ao aprendiz formular hipóteses com base no comportamento das estruturas nos contextos de uso da línguaalvo aos quais ele está exposto. Assim, erros resultantes da própria LE seriam mais comuns. As produções a seguir, exemplificam o fenômeno observado no teste postergado:

Quadro 2 - Texto produzido por AE3 e AI5 que ilustram a natureza dos erros mais comuns nos dois grupos.

\begin{tabular}{|c|c|}
\hline $\begin{array}{l}\text { AE3: Tutti giorni io faccio colazione alle } \\
\text { 7. Dopo, ando alla universidad e estudo } \\
\text { con mi amigi. Alle } 13 \text {, io mangio con mia } \\
\text { nona. Dopo faccio tutti la lezzioni e leggo } \\
\text { tutti il libro. Alle } 6 \text { de la sera, io preparo la } \\
\text { cena para mia famiglia e noi cenamo. Dopo } \\
\text { guardo la TV e è tutto finito. }\end{array}$ & $\begin{array}{l}\text { AI5: Alle } 8.00 \text { ho fatto colazione e dopo } \\
\text { faccio la docci vado a mio lavoro. Alle } \\
\text { 9:00 ho inicio mio lavoro a 13:00. Dopo } \\
\text { ho pranzo e dopo i ritorno a mio lavoro } \\
\text { a 20;00. Dopo ho vado mia casa com } \\
\text { mio marito. Noi mangiamo, ho ascolto la } \\
\text { musica, ho ledo livri, ho accendo le PC e } \\
\text { dopo ho vado a dormire. }\end{array}$ \\
\hline
\end{tabular}

Os verbos grifados nos textos de AE3 e AI5 foram conjugados incorretamente na $1^{\circ}$ pessoa do singular do presente dell'indicativo. No texto de AE3, as formas ando para o verbo andare e estudo para o verbo studiare sugerem a transferência de formas do português para o italiano, quando deveria ser vado e studio. Foram, portanto, considerados erros interlinguais. No texto de AI5, por outro lado, os verbos de $1^{\circ}$ pessoa do singular do presente dell'indicativo foram formulados com o uso de auxiliar (ho fatto, ho pranzo), assemelhando-se à construção 
do passato prossimo, ao qual o aluno havia sido exposto antes do teste postergado. Foram, portanto, considerados erros intralinguais. Cabe ainda salientar que, no texto de AI5, coexistem formas de $1^{\circ}$ pessoa do singular do presente dell'indicativo conjugadas corretamente (pranzo, vado, ascolto, accendo).

Em relação à complexidade sintática das produções do G1 e G2, foi possível observar um leve aumento no uso de frases subordinadas nas produções de ambos os grupos, do pré-teste para o teste imediato e desse para o teste postergado. No pré-teste, as produções eram compostas, essencialmente, por frases curtas, separadas por ponto e vírgula ou ponto final. Nos dois pós-testes, observamos o uso das conjunções quando e perché.

Os dados ainda mostraram que os textos produzidos no teste postergado pelo G2 foram um pouco mais complexos do que os textos produzidos pelo G1, tanto para a estrutura simples como para a estrutura complexa, como mostram os gráficos 3 e 4 a seguir.

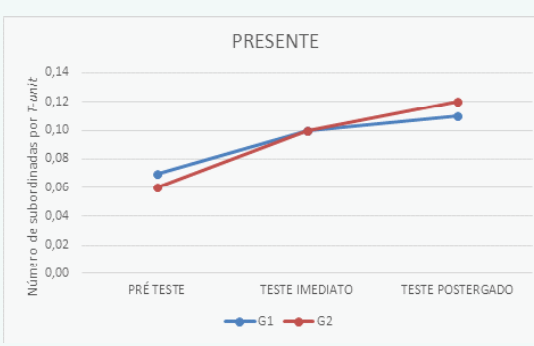

Gráfico 3. Complexidade sintática das produções do G1 e G2 nos testes com o presente dell'indicativo.

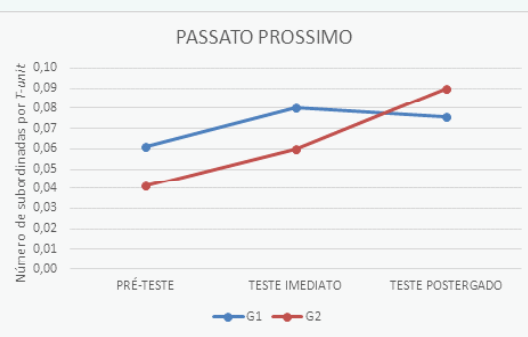

Gráfico 4. Complexidade sintática das produções do G1 e G2 nos testes com o passato prossimo.

De acordo com os gráficos acima, há um incremento maior de frases subordinadas no $\mathrm{G} 2 \mathrm{em}$ relação ao $\mathrm{G} 1$, do teste imediato para o teste postergado. Em termos numéricos, a diferença não é representativa, mas é possível sugerir que o ensino implícito contribuiu para a produção de textos sintaticamente mais complexos.

Com relação ao discurso produzido por ambos os grupos, os dados permitiram afirmar que os alunos do G2 imprimiram certa veracidade aos seus textos, deixando clara, em suas produções, a presença de um 
interlocutor (AI3 - ascolta Grillo!; AI8 - Ciao amica, come stai?; AI5 Signore carabiniere), a sua identidade pessoal (AI3-Ma questo no mi piace; AI8 - Però io penso che tu sei piu bella che Silvia) e emoções (AI5 - OH, paura!; che paura novamente!). Segundo Joy (2011), essa é uma maneira de o aluno dar autenticidade ao texto, construindo identidade própria numa comunidade discursiva específica de sala de aula. Podemos assim afirmar que o $\mathrm{G} 2$ buscou dar maior autenticidade à sua produção escrita.

No G1, por outro lado, as produções textuais não mostraram criar situações espontâneas de comunicação. Os textos se limitaram a frases que simplesmente contextualizavam o verbo, sem compromisso com o propósito comunicativo de seus enunciados. Essa tendência pode ser explicada pelo tipo de ensino ao qual o G1 foi exposto, isto é, marcado pela prática mecanizada que, por natureza, não engaja o aluno no comportamento comunicativo. O Quadro 3, a seguir, compara dois textos, um do G1 (AE4) e o outro do G2 (AI1), ambos referentes a uma das atividades de produção escrita ${ }^{14}$ do material instrucional.

Quadro 3 - Texto produzido por AE4 e AI1 contando o que fizeram em uma viagem pela Itália, a partir de ilustrações fornecidas.

AE4: Io ho visitato la citta de Roma ano passsado $i$ ho visitato Colosseo i ho comprato souveniers per mi famiglia. Io ho mangiato en un ristorante in Piazza Navona. Io ho fatto una foto nella Fontana di Trevi e ho jogato una moneta per tornare in Italia $[\ldots]$
AI1: Ciao amici, la settimana scorsa io ho visitato la Italia! Sette giorni... primo a Roma, Lei è uma belíssima città. Em mio primo giorno ho visitato il coloseo. è multo grande mesmo. Lá ho comprato regalos per tutta la famiglia. La sera ho serato en um ristorante nella piazza Navona. Una comida più buona! N'altro giorno io ho giocato una moneta nella Fontana di Trevi. Tu deve andare a Roma! [...]

No texto de AI1, observa-se a presença de um interlocutor (ciao amici), opiniões/ comentários (lei è uma bellissima città; è multo

14. Attività: Riceverai un cartoncino con figure di alcuni posti famosi d'Italia. Immagina che tu abbia visitato tutti questi posti in un viaggio di 7 giorni. In base alle figure, scrivi un testo, in italiano, raccontando a un(a) amico(a) cosa hai fatto durante il viaggio. [Atividade: Você receberá um cartãozinho com figuras de alguns lugares famosos da Itália. Imagina que você tenha visitado esses lugares em uma viagem de sete dias. Com base nas figuras, escreva um texto, em italiano, contando a um amigo o que você fez durante a viagem.] 
grande mesmo; una comida più buona) e conselhos (tu deve andare a Roma!), diferente da produção de AE4, que apresenta orações curtas, ligadas pela conjunção "e", nas quais o aluno justapõe as ações que teria realizado em sua viagem à Itália.

Com base nas análises aqui realizadas, passamos para as conclusões.

\section{Conclusão}

Este estudo mostrou haver relação entre as abordagens de ensino utilizadas e a produção escrita dos alunos. A abordagem explícita foi capaz de promover textos mais precisos, uma vez que a maioria dos alunos do G1 usou corretamente as formas de $1^{\mathrm{a}}$ e $3^{\mathrm{a}}$ pessoas do singular e de $3^{\mathrm{a}}$ pessoa do plural dos verbos regulares (-are, -ere e -ire) e irregulares (fare e andare), no presente dell'indicativo e no passato prossimo. A abordagem implícita também contribuiu para textos acurados; porém, sem tanta eficácia como a apresentada pela abordagem explícita.

É possível sugerir que o ensino explícito, nos moldes adotados - Apresentação, Prática e Produção, mostrou ser mais eficaz para a aprendizagem de ambas as estruturas do ItLE, a simples e a complexa. No entanto, não é possível generalizar esse dado, devido à quantidade limitada de alunos que participaram desta pesquisa.

Por outro lado, o ensino implícito nos moldes adotados - atividades comunicativas com insumo duplamente encharcado e destacado, provocou noticing das estruturas-alvo pelos alunos do G2, mas alguns não pareceram ter entendido as diferenças de usos entre as formas verbais, demonstrando estar em fase de apropriação dessas estruturas.

Embora a abordagem explícita tenha oferecido resultados melhores para o desenvolvimento da competência linguística dos alunos, ela não foi suficiente para promover o domínio pleno das estruturas-alvo. Nesse sentido, os dados corroboram a ideia de que a aprendizagem é um processo que leva tempo; não é linear e sofre constantes reestruturações à medida que novas informações (input) são introduzidas, independentemente da abordagem de ensino utilizada. 
É também possível afirmar a existência de uma relação entre as abordagens de ensino utilizadas e a natureza dos erros cometidos pelos alunos. O estudo mostrou que as produções do G1 e G2 apresentaram erros interlinguais, resultantes da transferência negativa do português e de outras LEs para a língua-alvo. Porém, com o tempo, o G2 começou a apresentar maior número de erros intralinguais, desencadeando processos de supergeneralização (overgeneralization) de formas aprendidas para casos em que a regra não se aplicava. A supergeneralização faz parte do processo natural de aquisição de uma língua (estrangeira e materna) e, portanto, mais propícia de acontecer no ensino implícito.

Os dados ainda permitiram afirmar que o ensino implícito pode ser benéfico para o desenvolvimento de textos complexos do ponto de vista sintático, lexical e discursivo, possivelmente em decorrência da exposição dos alunos a contextos de uso propositado da língua.

Em estudos futuros, seria interessante considerar uma população maior e mais homogênea em termos de idade para permitir a generalização dos dados. Da mesma forma, um terceiro grupo poderia ser criado, submetido a uma abordagem explícita sem a fase da produção comunicativa, de modo a verificar se os resultados obtidos nesta pesquisa para o G1 foram decorrentes da prática comunicativa ou da prática estrutural. Será que os resultados seriam os mesmos em um contexto cujo conhecimento declarativo fosse seguido somente de prática estrutural, sem a presença de prática comunicativa?

Recebido em: 07/03/2017

Aprovado em: 23/07/2017

E-mails: paulifreitas@hotmail.com rosely.xavier@ufsc.br

\section{Referências bibliográficas}

Anderson, J. R. 1982. Acquisition of cognitive skill. Psychological Review, v. 89/ 4: 369-406. 1993. Rules of the mind. New Jersey: Lawrence Erlbaum Associates.

Andrews, K. L. Z. 2007. The effects of implicit and explicit instruction on simple and complex grammatical structures for adult English 
language. TESL-EJ, v. 11/2: 1-13. Disponível em: <http://tesl-ej.org/ ej42/a5.html >. Acesso em 23/07/2011.

BALTHAZAR. L. L. 2009. Um olhar investigativo sobre as atividades orais de livros didáticos destinados a iniciantes de língua italiana. Dissertação (Mestrado em Educação), Universidade Federal de Santa Catarina, Florianópolis.

Banfi, E.; Bernini, G. 2003. Il verbo. In: Giacalone Ramat, A. (org.). Verso l'italiano. Roma: Carocci.

CARluCCI, L.; CASE, J. 2013. On the necessity of U-shaped learning. Topics in Cognitive Science, v. 5/ 1: 56-88.

Cepollaro, A. 2003. Come scegliere materiale televisivo autentico. Rivista In.it, anno 3/ 3: 22-26.

Conselho DA Europa. 2001. Quadro europeu comum de referência para as línguas. Aprendizagem, ensino e avaliação. Tradução do inglês de Maria Joana Pimentel do Rosário e Nuno Verdial Soares. PortoLisboa: Asa Edições.

Dardano, M.; Trifone, P. 2002. Grammatica italiana modulare. Bologna: Zanichelli.

Dekeyser, R. 1998. Beyond focus on form. Cognitive perspectives on learning and practicing second language grammar. In: Doughty, C.; Williams, J. (orgs.). Focus on form in classroom second language acquisition. Cambridge: CUP.

. 2003. Implicit and explicit learning. In: Doughty, C.; Long, M. (eds.). Handbook of second language acquisition. Oxford: Blackwell.

2007. Skill acquisition theory. In: Vanpatten, B.; Williams, J (eds.). Theories in second language acquisition: An introduction. New Jersey: Lawrence Erlbaum Associates.

ELLIS, R. 2004. The definition and measurement of explicit knowledge. Language Learning, n. 54: 227-275.

2009. Implicit and explicit learning, knowledge and instruction. In: Eldis, R.; Loewen, S.; Elder, C.; Erlam, R.; Philp, J.; Reinders, H. (orgs.). Implicit and explicit knowledge in second language learning, testing and teaching. Toronto: Multilingual Matters.

Ellis, R.; Barkhuizen, G. 2005. Analysing learner language. Oxford: OUP.

Freitas, P. G de. 2014. Os efeitos de duas estratégias de ensino, uma implícita e outra explícita, na aprendizagem do presente e do passato prossimo do italiano como língua estrangeira. Tese (Doutorado em Linguística), Universidade Federal de Santa Catarina, Florianópolis. 
HAN, Z.; PARK, E. S.; COMBS, C. 2008. Textual enhancement of input: issues and possibilities. Applied Linguistics, v. 29/ 4: 597-618.

Housen, A.; PierRARD, M. 2005. Investigating instructed second language acquisition. In: Housen, A.; Pierrard, M. (eds.) Investigations in instructed second language acquisition. Berlim: Mouton de Gruyter.

Hulstisn, J. 2005. Theoretical and empirical issues in the study of implicit and explicit second language learning: Introduction. Studies in Second Language Acquisition, v. 27/ 2: 129-140.

Hunt, K. W. 1970. Syntactic maturity in school children and adults. Monographs of the Society for Research in Child Development, $\mathbf{v}$. 35.

Joy, J. J. L. 2011 The duality of authenticity in ELT. The Journal of Language and Linguistic Studies, v. 7/ 2: 7-23.

Long, M. H.; Robinson, P. 1998. Focus on form: theory, research and practice. In: Doughty, C.; Williams, J. Focus on form in classroom second language acquisition. Cambridge: CUP.

Mclaughlin, B. 1987. Theories of second language acquisition. London: Edward Arnold.

NoRris, J. M.; OrtegA, L. 2000. Effectiveness of L2 instruction: a research synthesis and quantitative meta-analysis. Language Learning, n. 50: 417-528.

PARK, E. S. 2011. Learner-generated noticing of written L2 input: What do learners notice and why? Language Learning, v. 61/ 1: 146-185.

Polio, C. G. 1997. Measures of linguistics accuracy in second language writing research. Language Learning, v. 47/ 1: 101-147.

Roldão, M. C. 2007. Função docente: natureza e construção do conhecimento profissional. Revista Brasileira de Educação, v. 12/ 34: 94-103.

Sabatini, F. 1984. La comunicazione e gli usi della língua. Torino: Loescher editore, 1984.

SснміDт, R. 1990. The role of consciousness in second language learning. Applied Linguistics, v. 11/ 2: 129-158.

.1995. Consciousness and foreign language learning: a tutorial on the role of attention and awareness in learning. In: SCHMIDT, R. (ed.). Attention and awareness in foreign language learning. Second Language Teaching \& Curriculum Center, Havaí: Universidade do Havaí em Manoa. 2001. Attention. In: Robinson, P. (ed.). Cognition and second language instruction. Cambridge: CUP. 
2010. Attention, awareness, and individual differences in language learning. In: Chan, W. M.; ChI, S.; Cin, K. N.; Istanto, J.; Nagami, M.; Sew, J. W.; Suthiwan, T.; Walker, I. Proceedings of CLaSIC 2010. Singapore: Universidade Nacional de Singapura.

SerIANNI, L. 1989. Grammatica italiana. Torino: UTET Libreria.

Sharwood Smith, M. 1993. Input enhancement in instructed SLA: Theoretical bases. Studies in Second Language Acquisition, v. 15/ 2: $165-179$.

SkinNer, B. F. 1945. The operational analysis of psychological terms. Psychological Review. v. 52/ 4: 270-277.

Tomlin, R. S.; Villa, V. 1994. Attention in cognitive science and second language acquisition. Studies in Second Language Acquisition, v. 16/ 2: 183-203.

WidDowson, H. G. 1978. Teaching language as communication. Oxford: OUP.

Williams, J.; Evans, J. 1998. What kind of focus and on which forms? In: Doughty, C.; Williams, J. (eds.). Focus on form in classroom second language acquisition. Cambridge: CUP.

Zingarelli, N. 2005. Vocabolario della Lingua Italiana. Bolonha: Zanichelli. 